Ferrata Storti Foundation

\title{
Computed tomography pulmonary angiography versus ventilation-perfusion lung scanning for diagnosing pulmonary embolism during pregnancy: a systematic review and meta-analysis
}

Haematologica 2019

Volume 104(1):176-188

\section{Correspondence: \\ tromeurcecile@gmail.com}

Received: April 23, 2017.

Accepted: August 14, 2018.

Pre-published: August 16, 2018.

doi:10.3324/haematol.2018.196121

Check the online version for the most updated information on this article, online supplements, and information on authorship \& disclosures: www.haematologica.org/content/104/1/176

\section{(C)2019 Ferrata Storti Foundation}

Material published in Haematologica is covered by copyright. All rights are reserved to the Ferrata Storti Foundation. Use of published material is allowed under the following terms and conditions:

https://creativecommons.org/licenses/by-nc/4.0/legalcode. Copies of published material are allowed for personal or internal use. Sharing published material for non-commercial purposes is subject to the following conditions:

https://creativecommons.org/licenses/by-nc/4.0/legalcode, sect. 3. Reproducing and sharing published material for commercial purposes is not allowed without permission in writing from the publisher.

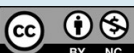

\author{
Cécile Tromeur, ${ }^{1,2,3}$ Liselotte M. van der Pol, ${ }^{1,4}$ Pierre-Yves Le Roux, ${ }^{5}$ Yvonne \\ Ende-Verhaar, ${ }^{1}$ Pierre-Yves Salaun, ${ }^{5}$ Christophe Leroyer, ${ }^{2,3}$ Francis Couturaud, ${ }^{2,3}$ \\ Lucia J.M. Kroft, ${ }^{6}$ Menno V. Huisman ${ }^{1}$ and Frederikus A. Klok ${ }^{1}$
}

\begin{abstract}
${ }^{1}$ Department of Thrombosis and Hemostasis, Leiden University Medical Center, the Netherlands; ' ${ }^{2}$ roupe d'Etude de la Thrombose de Bretagne Occidentale, University of Brest, Equipe d'Accueil 3878, Department of Internal Medicine and Chest Diseases, CHRU Brest, France; ${ }^{3}$ Centre d'Investigation Clinique INSERM 1412, University of Brest, France; ${ }^{4}$ Department of Internal Medicine, Haga Teaching Hospital, the Hague, the Netherlands; ${ }^{5}$ Département de Médecine Nucléaire, CHRU Brest, France and ${ }^{6}$ Department of Radiology, Leiden University Medical Center, the Netherlands
\end{abstract}

\section{ABSTRACT}

$\mathrm{D}$ ifferences between computed tomography pulmonary angiography and ventilation-perfusion lung scanning in pregnant patients with suspected acute pulmonary embolism are not well-known, leading to ongoing debate on which test to choose. We searched in PubMed, EMBASE, Web of Science and the Cochrane Library databases and identified all relevant articles and abstracts published up to October 1, 2017. We assessed diagnostic efficiency, frequency of non-diagnostic results and maternal and fetal exposure to radiation exposure. We included 13 studies for the diagnostic efficiency analysis, 30 for the analysis of non-diagnostic results and 22 for the radiation exposure analysis. The pooled rate of false negative test results was $0 \%$ for both imaging strategies with overlapping confidence intervals. The pooled rates of non-diagnostic results with computed tomography pulmonary angiography and ventilation-perfusion lung scans were $12 \%$ (95\% confidence interval: 8 17) and 14\% (95\% confidence interval: 10-18), respectively. Reported maternal and fetal radiation exposure doses were well below the safety threshold, but could not be compared between the two diagnostic methods given the lack of high quality data. Both imaging tests seem equally safe to rule out pulmonary embolism in pregnancy. We found no significant differences in efficiency and radiation exposures between computed tomography pulmonary angiography and ventilation-perfusion lung scanning although direct comparisons were not possible.

\section{Introduction}

Pulmonary embolism (PE) is a major complication of pregnancy and responsible for $2 \%$ to $14 \%$ of all maternal deaths worldwide. ${ }^{1,2}$ Although accurate diagnostic tests for $\mathrm{PE}$ are essential for this specific population, high quality diagnostic studies are unavailable. ${ }^{3}$ Clinical decision rules, which are the cornerstone of PE diagnostic management in the non-pregnant population, were not developed for, nor validated in pregnant patients. ${ }^{4}$ Furthermore, considering the physiological increase of D-dimer levels throughout pregnancy, the optimal D-dimer threshold to rule out $\mathrm{PE}$ is unknown. ${ }^{5}$ The application of $\mathrm{D}$-dimer tests and clinical decision rules as the initial step of the diagnostic algorithm for suspected PE cannot, therefore, be recommended in pregnant patients. ${ }^{3}$

Moreover, the optimal choice of imaging test to rule out or confirm acute PE in 
pregnant patients is highly debated. The two most used imaging tests for suspected acute PE in the non-pregnant population are computed tomography pulmonary angiography (CTPA) and ventilation-perfusion (V-O) lung scanning, with CTPA being the imaging test of choice because of its high accuracy, wide availability, and ability to exclude other pathologies. ${ }^{6,7}$ As is generally the case with V-O lung scans, the risk of non-diagnostic tests with CTPA is relatively high, in part because of the hemodynamic changes that occur during pregnancy, such as hemodilution and increased heart rate, which make it necessary to have a CTPA protocol specifically designed for pregnant patients. Additionally, elevation of the diaphragm, due to the enlarged uterus, accentuates the interruption of contrast by non-opacified blood from the inferior vena cava and may lead to decreased contrast attenuation in areas of the pulmonary arteries. ${ }^{6}$ Moreover, both CTPA and V-O lung scanning involve exposure of the fetus and patients' breasts to radiation. The lack of high quality management studies comparing both imaging tests fuels an ongoing debate in the literature on which of the two options should be preferred.

We set out to perform a systematic review and metaanalysis of published literature to compare the diagnostic efficiency of CTPA versus $\mathrm{V}-\mathrm{O}$ lung scans in pregnant patients with suspected acute PE. We also aimed to compare the rate of non-diagnostic scan results and radiation exposure for both the mother and fetus.

\section{Methods}

\section{Search strategy}

For this meta-analysis, we conducted a search for all relevant full publications in PubMed, EMBASE, Web of Science and the Cochrane Library databases. We searched EMBASE, Web of Science and the Cochrane library databases for relevant meeting-abstracts as well. The complete search strategy is detailed in Online Supplementary Appendix A.

\section{Selection of studies}

Search results were combined and duplicates were removed. Studies were screened for relevance by two independent reviewers (CT and LvdP) following a specific three-step program and applying Covidence software (www.covidence.org). Disagreements were resolved by a third investigator (FK) by majority rule. The first and second steps consisted of title and abstract screening followed by full text screening for the remaining articles. The final selection of the studies to include in the meta-analysis was based on assessment of relevance and study quality. The assessment of relevance was based on the following criteria: (i) prospective patient inclusion, (ii) inclusion of consecutive patients, (iii) reported rate of non-diagnostic test results, and (iv) reported incidence of PE at baseline. The assessment of bias was evaluated in accordance with the PRISMA criteria: ${ }^{8}$ (i) pre-specified study protocol, (ii) clear description of inclusion and exclusion criteria, (iii) inclusion of consecutive patients, (iv) objective diagnosis of PE, (v) reported losses to follow-up, (vi) clear distinction between pregnant and post-partum patients, and (vii) assessment of the primary endpoints in all patients. Studies were included in the meta-analyses according to the definition of each endpoint.

The final step was data extraction. For each included study, we extracted the first author's name and year of publication, study design (prospective or retrospective), setting of the study (single- or multicenter), number of patients in the index cohort, the baseline incidence of PE, the duration of follow up, and the predefined study endpoints.

\section{Study outcomes and definitions}

We predefined three major study endpoints. The first was the diagnostic efficiency of both imaging tests as expressed by the number of false negative scans. This first outcome required a follow up of at least 3 months as well as reporting of the number of diagnosed PE events during this follow up. The second endpoint was the rate of non-diagnostic results with CTPA and V-Q lung scans. For CTPA, scan results were defined non-diagnostic when the radiologist was unable to confirm or exclude the diagnosis of $\mathrm{PE}$, usually because of suboptimal contrast opacification and respiratory motion artifacts, or the need for an additional imaging test. For V-O lung scanning, the definition of non-diagnostic results was based on the PIOPED criteria, i.e. intermediate and low probability scan results, since these require an additional diagnostic test to confirm or rule out PE with sufficient certainty. The third endpoint was fetal and maternal radiation exposure due to CTPA and V-Q lung scanning. The CTPA radiation exposure was collected for studies in real-life patients as well as with anthropometric phantom models simulating a gravid woman.

\section{Statistical analysis}

The baseline incidence of $\mathrm{PE}$ and rate of false negative scans were calculated with corresponding $95 \%$ confidence intervals (95\% CI). The number of non-diagnostic results from all studies was collected and the rate of non-diagnostic results was calculated using the number of non-diagnostic tests divided by the number of patients in each study. We applied a random effects model according to DerSimonian and Laird for the calculation of the pooled rates of the four study endpoints. ${ }^{9}$ We predefined that we would not undertake data pooling in case studies for any of the three endpoints because they were not comparable due to extensive differences in study design or imaging protocols, which do not allow for reliable statistics or data pooling. Heterogeneity across the various cohort studies was assessed by calculating the $\mathrm{I}^{2}$ statistic. Heterogeneity was defined as low when $\mathrm{I}^{2}$ was $<25 \%$, intermediate when $\mathrm{I}^{2}$ was $25-75 \%$ and high when $\mathrm{I}^{2}$ was $>75 \% .{ }^{10}$ All analyses were performed in Stata 14.0 (Stata Corp., College Station, TX, USA).

\section{Results}

\section{Study selection}

The initial search identified 303 records in PubMed, 318 articles in EMBASE, 76 articles in Web of Science, and three articles in the Cochrane Library. After a first screening of titles and abstracts, 565 articles were excluded. A further 78 articles were excluded based on the predefined inclusion criteria (Figure 1): 20 studies did not report the study outcomes of interest, two articles concerned thyroid function after CTPA, five articles involved surveys about clinical practice, two articles were duplicates, four were guidelines, five were letters to the editor and did not report the outcomes of interest, 37 were review articles and four were irrelevant case reports. Two additional relevant articles were identified after reviewing the references lists of the selected studies. A final 49 evidencebased studies were fully assessed for study quality ${ }^{6,7,11-57}$ (Table 1): 13 were included in the analysis of false nega-

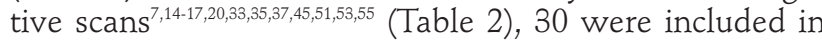
the analysis of non-diagnostic results ${ }^{7,14-17,19-21,23-29,32-37,45,46,49,52-57}$ 
(Table 3), and 11 were included in the radiation exposure analysis ${ }^{16,18,20,21,24,28,33,34,52,54,57}$ (Table 4). Finally, 11 studies involving anthropometric phantoms simulating pregnancy were also included ${ }^{58-68}$ (Table 5).

\section{First study endpoint: diagnostic accuracy}

A total of 13 relevant studies were selected to study the rate of false negative CTPA and V-O lung scan examinations. ${ }^{7} 14-17,20,33,35,37,45,51,53,55$ These studies were published between $1997^{14}$ and $2017,53,55$ and involved a total of 1270 patients investigated with $\mathrm{V}-\mathrm{O}$ lung scanning and 837 patients investigated with CTPA (Table 2). Data were extracted from ten full text articles s $^{7,14-17,20,33,35,37,55}$ and three meeting abstracts. ${ }^{45,51,53}$ Only one of these 13 studies was a prospective study in 143 patients investigated with CTPA. ${ }^{45}$ The prevalence of PE ranged between $0 \%$ and $22.2 \%$, ${ }^{35}$ with the highest prevalences in the few smaller studies (median $4.1 \%$ ). The duration of follow up varied from at least 3 months to 24 months. ${ }^{35}$ In two studies, the total duration of follow up was not reported. ${ }^{14,17}$ None of the 1270 patients investigated with V-O lung scanning was diagnosed with recurrent $\mathrm{PE}$ or deep vein thrombosis (DVT) during follow up, resulting in a pooled number of false negative scans of $0 \%\left(95 \%\right.$ CI: $\left.0-0.04 ; \mathrm{I}^{2}=0.0\right)$. Three of 837 patients were diagnosed with non-fatal PE after a normal initial CTPA, for a pooled number of false negative scans of $0.0 \%\left(95 \% \mathrm{CI}: 0.0-0.16 ; \mathrm{I}^{2}=5.7\right)$ in the CTPA group (Figure 2). The risk of bias was high in two studies, ${ }^{17,51}$ moderate in nine studies ${ }^{7,14-16,20,33,35,45,53}$ and low in only two studies ${ }^{37,55}$ (Table 1 ).

\section{Second study endpoint: non-diagnostic results}

A total of 30 relevant studies were selected to evaluate the rate of non-diagnostic or inconclusive results of $\mathrm{V}-\mathrm{O}$ lung scans or CTPA. .,14-17,19-21,23-29,32-37,45,46,49,52-57 These studies involved a total of 2535 patients investigated with $\mathrm{V}$-Q lung scanning and 1774 patients assessed by CTPA (Table 3). The rate of non-diagnostic results with V-O lung scanning ranged from $1.3 \%{ }^{36}$ to $40 \%{ }^{14}$ whereas the rate of non-diagnostic results with CTPA ranged from $0 \%{ }^{19}$ to $57.1 \%{ }^{23,56}$ The rate of additional imaging tests after a first non-diagnostic V-O lung scan ranged from $14 \%{ }^{37}$ to $100 \%{ }^{23,27}$ whereas it ranged from $0 \%{ }^{35}$ to $62 \%{ }^{15}$ after a first non-diagnostic CTPA. The pooled rates of non-diagnostic test results with V-O lung scanning and with CTPA were 14\% (95\% CI: 10$18, \mathrm{I}^{2}=90.30 \%$ ) and $12 \%$ (95\% CI: $6-17, \mathrm{I}^{2}=93.86 \%$ ), respectively. The $95 \%$ confidence intervals of the non-diagnostic rate values overlap (Figure 3 ). The risk of bias was high in 16 studies, ${ }^{17,19,21,24-28,32,34,36,46,49,54,56,57}$ moderate in 12 studies $^{7,14}$ $16,20,23,29,33,35,45,52,53$ and low in only two studies ${ }^{37,55}$ (Table 1).

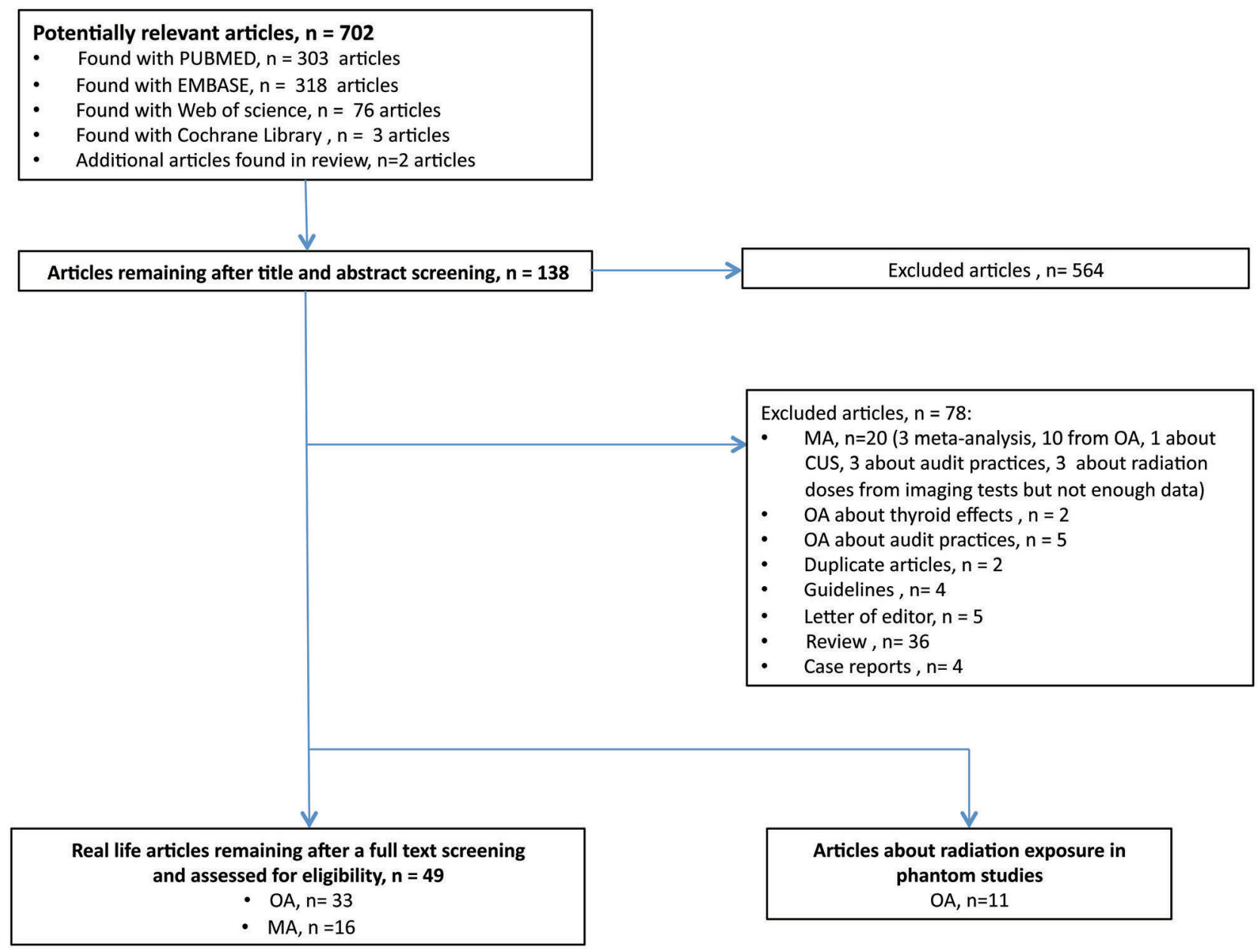

Figure 1. Flow chart of the systematic review. MA: meeting abstract; OA: original article; CUS: compression ultrasonography. 
Table 1. Assessment of relevance and bias of the included studies.

\begin{tabular}{|c|c|c|c|c|c|c|c|c|c|c|c|c|c|c|}
\hline \multirow[b]{2}{*}{ Article } & \multicolumn{6}{|c|}{ Assessment of relevance } & \multicolumn{4}{|c|}{ Assessment of bias } & \multirow{2}{*}{\begin{tabular}{|c|}
$\begin{array}{c}\text { Overall } \\
\text { risk of } \\
\text { bias }\end{array}$ \\
Bias in a \\
certain \\
direction?
\end{tabular}} & \multirow{2}{*}{\begin{tabular}{|c|}
$\begin{array}{c}\text { Study } \\
\text { included }\end{array}$ \\
\\
False \\
negati \\
ve \\
tests
\end{tabular}} & \multirow{2}{*}{\begin{tabular}{|c|}
$\begin{array}{c}\text { Study } \\
\text { included }\end{array}$ \\
\\
Non \\
diagnos \\
tic \\
imaging \\
test \\
\end{tabular}} & \multirow{2}{*}{\begin{tabular}{|c|}
$\begin{array}{c}\text { Study } \\
\text { included }\end{array}$ \\
\\
Radiati \\
on \\
exposu \\
re
\end{tabular}} \\
\hline & $\begin{array}{l}\text { Samp } \\
\text { le } \\
\text { size }\end{array}$ & $\begin{array}{l}\text { Prospecti } \\
\text { ve study }\end{array}$ & $\begin{array}{c}\text { Cohort of } \\
\text { consecuti } \\
\text { ve } \\
\text { patients }\end{array}$ & $\begin{array}{c}\text { Multicen } \\
\text { ter }\end{array}$ & $\begin{array}{l}\text { Non } \\
\text { diagnos } \\
\text { tic } \\
\text { results } \\
\text { reporte } \\
\quad \text { d }\end{array}$ & $\begin{array}{c}\text { PE } \\
\text { inciden } \\
\text { ce } \\
\text { reporte } \\
\text { d }\end{array}$ & $\begin{array}{l}\text { Follo } \\
\text { w up }\end{array}$ & $\begin{array}{c}\text { Comple } \\
\text { te } \\
\text { follow } \\
\text { up }<5 \%\end{array}$ & $\begin{array}{l}\text { Representat } \\
\text { ive } \\
\text { population }\end{array}$ & $\begin{array}{c}\text { Quality } \\
\text { of PE } \\
\text { diagnosis } \\
\text { (accordin } \\
\mathrm{g} \text { to the } \\
\text { guideline } \\
\text { s) }\end{array}$ & & & & \\
\hline $\begin{array}{l}\text { Andreou } \\
\text { et al.2008 }\end{array}$ & 16 & ○ & 0 & ○ & 0 & 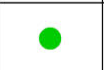 & ○ & ○ & 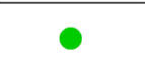 & e & ○ & ○ & 0 & ○ \\
\hline $\begin{array}{l}\text { Bourjeily } \\
\text { et al. } 2012\end{array}$ & 343 & 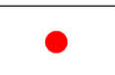 & ○ & ○ & ○ & 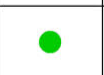 & ○ & - & ○ & - & O & ○ & - & 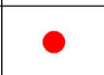 \\
\hline $\begin{array}{l}\text { Browne et } \\
\text { al.2014 }\end{array}$ & 70 & ○ & 0 & $\bullet$ & ○ & ○ & ○ & ○ & 0 & 0 & e & 0 & ○ & ? \\
\hline $\begin{array}{l}\text { Jordan et } \\
\text { al.2015 }\end{array}$ & 34 & 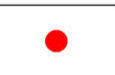 & 0 & ○ & O & ○ & ○ & ○ & O & 0 & ○ & ○ & ○ & ○ \\
\hline $\begin{array}{l}\text { King-Im et } \\
\text { al. } 2008\end{array}$ & 40 & ○ & 0 & ○ & ○ & ○ & 0 & ○ & ○ & 0 & ○ & ○ & ○ & ○ \\
\hline $\begin{array}{l}\text { Moradi et } \\
\text { al. } 2015\end{array}$ & 27 & ○ & ○ & ○ & - & 0 & ○ & ○ & ○ & ○ & O & - & 0 & ? \\
\hline $\begin{array}{l}\text { Shahir et } \\
\text { al.2015 }\end{array}$ & 36 & ○ & O & ○ & - & ○ & 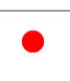 & ○ & ○ & 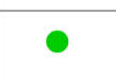 & ○ & 0 & 0 & ○ \\
\hline $\begin{array}{l}\text { Litmanovi } \\
\text { tch et } \\
\text { al. } 2009\end{array}$ & 26 & 0 & 0 & 0 & 0 & 0 & 0 & 0 & 0 & 0 & 0 & 0 & 0 & 0 \\
\hline $\begin{array}{l}\text { Ridge et } \\
\text { al.2011 }\end{array}$ & 45 & 0 & 0 & 0 & 0 & 0 & 0 & 0 & 0 & 0 & 0 & 0 & 0 & 0 \\
\hline $\begin{array}{l}\text { Abujudeh } \\
\text { et al.20099 }\end{array}$ & 14 & 0 & 0 & 0 & 0 & 0 & 0 & 0 & 0 & 0 & 0 & 0 & 0 & 0 \\
\hline $\begin{array}{l}\text { Ridge et } \\
\text { al.2009 }\end{array}$ & 50 & 0 & 0 & 0 & 0 & 0 & 0 & 0 & 0 & - & 0 & 0 & 0 & 0 \\
\hline $\begin{array}{l}\text { Moriarty } \\
\text { et al. } 2015\end{array}$ & 100 & ○ & 0 & 0 & 0 & 0 & $\theta$ & 0 & 0 & - & 0 & 0 & 0 & 0 \\
\hline $\begin{array}{l}\text { Balan et } \\
\text { al.1997 }\end{array}$ & 82 & 0 & 0 & 0 & 0 & 0 & 0 & 0 & 0 & 0 & 0 & - & - & ○ \\
\hline $\begin{array}{l}\text { Sellem et } \\
\text { al.2013 }\end{array}$ & 116 & 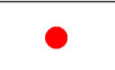 & 0 & 0 & 0 & 0 & 0 & 0 & 0 & 0 & 0 & 0 & 0 & 0 \\
\hline $\begin{array}{l}\text { Chan et al. } \\
2002\end{array}$ & 120 & 0 & 0 & 0 & 0 & 0 & 0 & 0 & 0 & 0 & 0 & 0 & 0 & 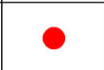 \\
\hline $\begin{array}{l}\text { Angulo et } \\
\text { al.2004 }\end{array}$ & 30 & 0 & 0 & 0 & 0 & 0 & 0 & 0 & 0 & 0 & 0 & 0 & 0 & 0 \\
\hline $\begin{array}{l}\text { Cutts et } \\
\text { al.2014 }\end{array}$ & 183 & 0 & 0 & ○ & 0 & 0 & 0 & 0 & 0 & 0 & 0 & 0 & 0 & 0 \\
\hline $\begin{array}{l}\text { Bajc et al. } \\
2015\end{array}$ & 127 & 0 & 0 & 0 & 0 & 0 & 0 & 0 & 0 & 0 & 0 & 0 & 0 & 0 \\
\hline $\begin{array}{l}\text { Richard et } \\
\text { al.2015 }\end{array}$ & 77 & $\bullet$ & 0 & 0 & 0 & 0 & 0 & 0 & 0 & 0 & 0 & 0 & 0 & 0 \\
\hline $\begin{array}{l}\text { Cahill et } \\
\text { al.2009 }\end{array}$ & 199 & 0 & 0 & 0 & - & 0 & 0 & 0 & 0 & 0 & 0 & 0 & 0 & 0 \\
\hline
\end{tabular}


continued from the previous page

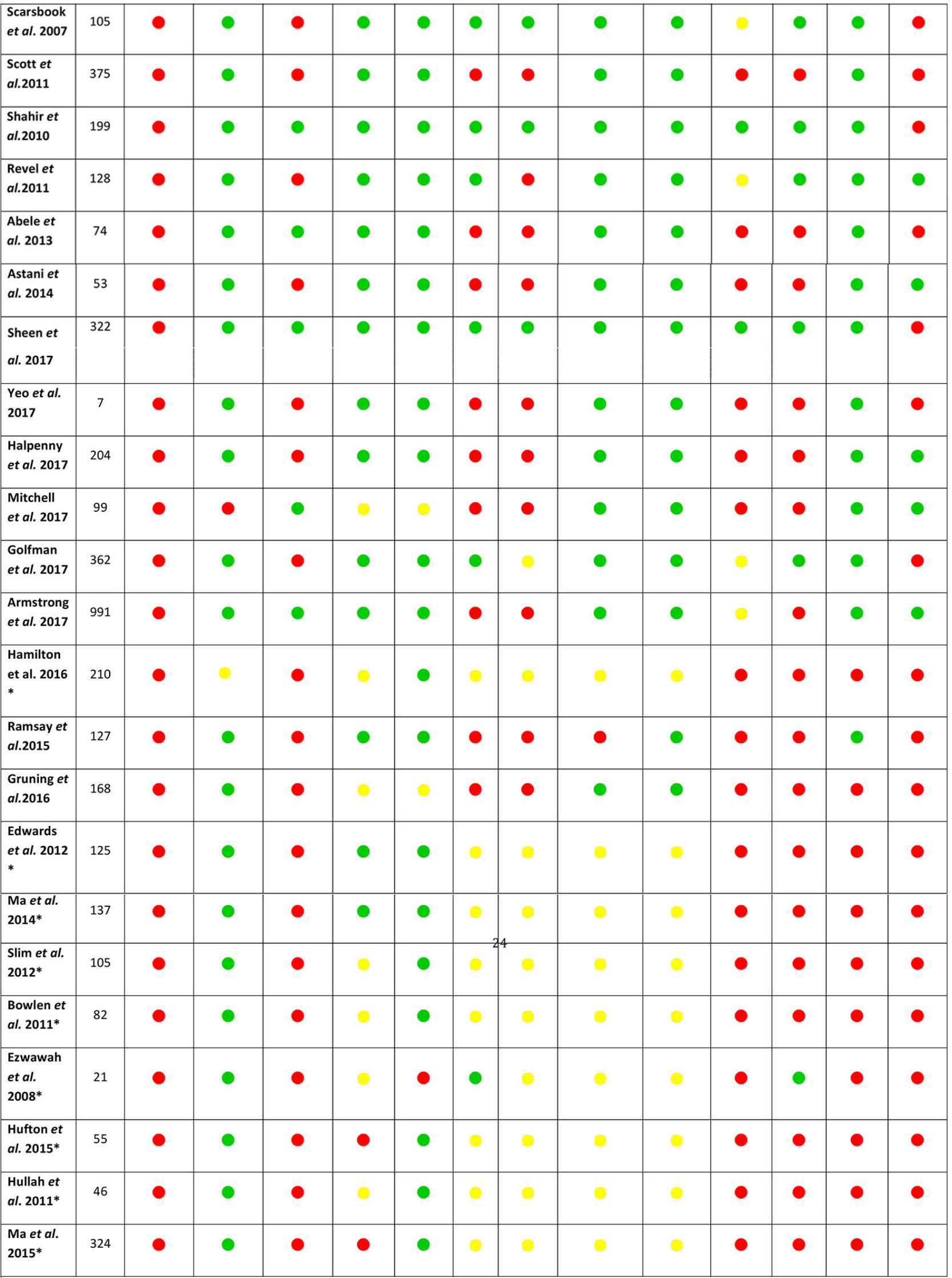




\begin{tabular}{|c|c|c|c|c|c|c|c|c|c|c|c|c|c|c|}
\hline $\begin{array}{l}\text { Butt et al. } \\
\text { 2011** }\end{array}$ & 105 & • & • & • & e & • & 0 & 0 & ○ & ○ & • & • & • & $\bullet$ \\
\hline $\begin{array}{l}\text { Vanes et } \\
\text { al. 2014* }\end{array}$ & 99 & • & • & - & • & • & 0 & • & e & 0 & • & • & • & • \\
\hline $\begin{array}{l}\text { Tomas et } \\
\text { al.2013* }\end{array}$ & 75 & $\bullet$ & • & • & • & • & - & 0 & 0 & 0 & • & • & • & $\bullet$ \\
\hline $\begin{array}{l}\text { Nijkeuter } \\
\text { et al. } \\
\text { 2013* }\end{array}$ & 149 & - & • & • & • & - & • & • & - & - & • & • & • & - \\
\hline $\begin{array}{l}\text { Potton et } \\
\text { al. 2009* }\end{array}$ & 34 & • & • & • & • & • & 0 & 0 & 0 & 0 & • & • & • & • \\
\hline $\begin{array}{l}\text { Roseverne } \\
\text { et al. } \\
2011^{*}\end{array}$ & 27 & • & 0 & • & • & • & 0 & 0 & 0 & 0 & • & • & • & • \\
\hline
\end{tabular}

$\begin{array}{lc}\text { unknown or unclear } & \text { overall riska } \\ \text { no } & \text { low risk } \\ \text { Follow up } & \text { modera } \\ \text { follow up not indicated/ follow up <3months } & \\ \text { no follow up } & \\ \text { Representative population: patient selection } & \\ \text { no distinction between post-partum and pregnant patient } & \\ \text { not pregnant patient } & \end{array}$

\section{Third study endpoint: radiation exposure}

Eleven clinically based studies were selected to compare radiation exposure during CTPA and V-O lung scanning. ${ }^{16,18,20,21,2,2,2,2,3,3,3,4,5,5,5,57}$ The mean maternal effective dose ranged from 0.9 to 5.85 milliSievert $(\mathrm{mSv})$ with $\mathrm{V}$-Q lung scanning and from 0.23 to $9.7 \mathrm{mSv}$ with CTPA (Table 4). The fetal/uterus absorbed dose ranged from 0.2 to 0.7 milliGray (mGy) with V-Q lung scanning and from 0.002 to $0.51 \mathrm{mGy}$ with CTPA. ${ }^{28}$ Direct comparisons between V-O lung scanning and CTPA were not possible because of variations in the imaging protocols used and the methods of measuring or calculating radiation exposure. The dose-length product (DLP) was available in four studies: $: 16,20,21,57$ it ranged from $69.34 \pm 10.95 \mathrm{mGy} / \mathrm{cm}^{57}$ to $397.54 \pm 100.4 \mathrm{mGy} / \mathrm{cm} .{ }^{16}$ Because of the large differences in the applied, mostly unstandardized CTPA protocols among these studies, we refrained from data pooling.

A total of 11 relevant studies assessing CTPA radiation exposure in female phantoms showed that the mean maternal effective dose ranged from $2.5 \mathrm{mSv}^{58}$ to 4.9 $\mathrm{mSv}{ }^{59}$ (Table 5). The fetal/uterus absorbed dose ranged from $0.003 \mathrm{mGy}^{66}$ to $0.73 \mathrm{mGy} .{ }^{67}$ These results from the phantom studies should be interpreted with caution and may not be directly extrapolated to clinical practice because of the wide variations in scan techniques and methods of measuring and/or calculating the radiation exposure. No phantom studies with $\mathrm{V}-\mathrm{O}$ lung scanning were available.

\section{Discussion}

Our systematic review and meta-analysis provides an overview of all published literature on diagnostic accura$c y$, scan efficiency and radiation exposure dose of $\mathrm{V}-\mathrm{O}$ lung scans versus CTPA in pregnant patients with suspected acute PE. The negative predictive value and rates of non-diagnostic tests were comparable between V-Q lung scans and CTPA, although significant heterogeneity, overall high risk of bias and absence of direct comparisons prevent definite conclusions. Moreover and importantly, studies included in the meta-analysis are mostly outdated and none of the available studies evaluated state-of-theart imaging techniques as currently used in clinical practice. Maternal and fetal radiation exposure with CTPA and V-O lung scanning could not be compared because of lack of homogeneity in radiation calculation methods and large differences between the scan protocols used. However, all reported radiation measurements for both imaging techniques were clearly below the established harmful threshold of $100 \mathrm{mGy}^{69}$

The pooled failure rate for both imaging modalities was negligible, suggesting that both CTPA and V-O lung scanning can equally safely exclude PE during pregnancy. Our findings are concordant with those recently reported. ${ }^{70}$ Indeed, in the Cochrane review including 11 studies with 695 CTPA and $665 \mathrm{~V}-\mathrm{O}$ lung scan results, the median negative predictive value for both imaging techniques was 
$100 \% .^{70}$ The very high negative predictive values need to be interpreted on the background of the very low prevalence of $\mathrm{PE}$, which varied between $1 \%$ and $7 \%$ in the studies evaluated, implying a very low post-test probability of PE even with less than optimal sensitivity of a diagnostic test ${ }^{71}$ Only if current active trials confirm the safety of using the clinical decision rule and a D-dimer test to select patients with a higher pre-test probability of $\mathrm{PE}$, could the diagnostic safety of CTPA and VQ-lung scanning be better tested and compared. ${ }^{3,72}$ Notably, increasing the level of suspicion of $\mathrm{PE}$ with a specific strategy during pregnancy may lead to a lower negative predictive value of both CTPA and V-O lung scanning.

It has been widely acknowledged that, in contrast to CTPA, the risk of a non-diagnostic test result with $\mathrm{V}-\mathrm{O}$ lung scanning is considerable. Importantly, we found that the pooled risks of a non-diagnostic test for both imaging tests in the setting of pregnant patients with suspected PE were comparable. These pooled risks need to be put in perspective. For CTPA, a non-conclusive result was defined as suboptimal contrast opacification and respiratory motion artifacts that did not allow for a certain inclusion or exclusion of $\mathrm{PE}$. For $\mathrm{V}-\mathrm{Q}$ lung scanning, we defined non-diagnostic or inconclusive results according to the PIOPED criteria as intermediate and low probability scan results. ${ }^{73}$ We found considerably higher rates of non-diagnostic results with CTPA and V-O lung scanning than those reported in a recent Cochrane review. ${ }^{70}$
Notably, the definition of non-diagnostic tests was not provided in the Cochrane review and, based on our results, was probably underestimated. Indeed, most of the retrospective studies included in the Cochrane review used intermediate probability $\mathrm{V}-\mathrm{O}$ lung scan results as the definition of non-diagnostic results and low probability scans as normal scans whereas we classified low and intermediate probability scan results as non-conclusive. Importantly, clinical probability assessed by clinical judgement or a validated prediction rule is essential for the correct interpretation of a V-O lung scan: a non-diagnostic V-Q lung scan may exclude PE when combined with negative proximal compression ultrasound sonography in patients with a low clinical probability of PE. ${ }^{73}$ Compression ultrasound sonography may also be helpful when combined with an intermediate V-O lung scan probability to confirm or rule out acute PE. Unfortunately, such information was not provided by the studies identified. Therefore, the rate of non-diagnostic $\mathrm{V}-\mathrm{O}$ lung scans in our analysis may be biased towards overestimation. Again, the lack of direct comparisons and studies evaluating state-of-the art imaging protocols does not allow for definite conclusions. Of note, we cannot rule out the potential bias that while standard V-O scan reporting involves a statement on non-diagnostic results, this is not the case for CTPA.

It is generally known that CTPA results in relatively higher maternal radiation exposure but lower fetal

Table 2. Analysis of the rate of false negative test results after V-Q lung scans and CTPA.

\begin{tabular}{|c|c|c|c|c|c|c|}
\hline Study & $\begin{array}{c}\text { Number of patients } \\
\text { subjected to imaging } \\
\text { test (n) }\end{array}$ & $\begin{array}{c}\text { Baseline } \\
\text { PE prevalence }\end{array}$ & $\begin{array}{l}\text { Number of true } \\
\text { negative test }(n)\end{array}$ & $\begin{array}{l}\text { Number } \\
\text { of VTE } \\
\text { during } \\
\text { follow-up (n) }\end{array}$ & $\begin{array}{l}\text { NPV (\%), } \\
95 \% \text { Cl }\end{array}$ & $\begin{array}{l}\text { Duration of } \\
\text { follow-up } \\
\text { (months) }\end{array}$ \\
\hline
\end{tabular}

\begin{tabular}{lcccccc} 
& \multicolumn{3}{c}{ V-Q lung scanning } & & \\
Balan et al. 1997 & 82 & $22 \%(18 / 82)$ & 31 & 0 & $100,(88.97-100)$ & NP \\
Chan et al. 2002 & 113 & $7.1 \%(8 / 113)$ & 83 & 0 & $100,(95.58-100)$ & 6 \\
\hline Scarsbook et al. $2007^{*}$ & 96 & $1.0 \%(1 / 96)$ & 89 & 0 & $100,(95.86-100)$ & 24.5 \\
Ezwawah et al. 2008 & 19 & $\mathrm{NP}$ & 19 & 0 & $100,(83.18-100)$ & 3 \\
\hline Shahir et al. $2010^{* *}$ & 99 & $1 \%(1 / 99)$ & 77 & 0 & $100,(95.25-100)$ & 3 \\
Revelet al. 2011 & 91 & $11 \%(10 / 91)$ & 64 & 0 & $100,(94.34-100)$ & 3 \\
\hline Cutts et al. 2014 & 183 & $2.2 \%(4 / 183)$ & 173 & 0 & $100,(97.83-100)$ & NP \\
Sheen et al. 2017 & 225 & $2.7 \%(6 / 225)$ & 198 & 0 & $100(98.10-100)$ & 3 \\
\hline Golfam et al. 2017 & 362 & $4.7 \%(17 / 363)$ & 316 & 0 & $100(98.95-100)$ & 3
\end{tabular}

\begin{tabular}{lcc} 
Scarsbook et al. 2007 & 9 & $22.2 \%(2 /$ \\
Litmanovitch et al. 2009 & 26 & $0 \%(0 / 26)$ \\
\hline Shahir et al. 2010 & 106 & $3.7 \%(4 / 106)$ \\
Revel et al. 2011 & 43 & $16 \%(7 / 4)$ \\
\hline Bourjeily et al. 2012 & 343 & $2.6 \%(9 / 3$
\end{tabular}

\section{CTPA}

\begin{tabular}{lcccccc} 
Browne et al. 2014 & 70 & $1.4 \%(1 / 70)$ & 69 & 0 & $100,(94.73-100)$ & 6 \\
\hline Nijkeuter et al. 2013 & 143 & $4.2 \%(6 / 143)$ & 129 & 0 & $100,(97.11-100)$ & 3 \\
Sheen et al. 2017 & 97 & $4.1 \%(4 / 97)$ & 84 & 2 & $97.94,(99.43-92.79)$ & 3 \\
\hline
\end{tabular}

PE: pulmonary embolism;VTE: venous tromboembolism; NPV: negative predictive value; CI: confidence intervals; NP: not provided;V-Q scanning: ventilation perfusion scanning. CTPA: computed tomography pulmonary angiography; * one PE was diagnosed after 3 months of follow-up. **very low PE probability V-Q lung scans are considered as normal $\mathrm{V}-\mathrm{Q}$ lung scans. 
absorbed doses than V-Q lung scanning. Importantly, most of the radiation exposures reported in the literature were not measured directly but were calculated and, therefore, fully dependent on the scan techniques used, which were largely outdated compared to the ones currently used. The higher breast radiation exposure with

Table 3. Analysis of rate of non-diagnostic test results of $\mathrm{V}-\mathrm{Q}$ lung scanning and CTPA.

\begin{tabular}{|c|c|c|c|c|c|c|c|c|c|}
\hline Study & $\begin{array}{l}\text { Number of } \\
\text { patients } \\
\text { subjected } \\
\text { to imaging } \\
\text { test (n) }\end{array}$ & $\begin{array}{l}\text { Non-dlagnostic } \\
\text { imaging } \\
\text { test (n) }\end{array}$ & $\begin{array}{l}\text { Non-diagnostic } \\
\text { imaging } \\
\text { test }(\%)\end{array}$ & $\begin{array}{l}\text { Additional } \\
\text { imaging tests } \\
\text { in case of first } \\
\text { non-diagnostic } \\
\text { test. n (\%) }\end{array}$ & $\begin{array}{l}\text { Additional } \\
\text { imaging test }\end{array}$ & $\begin{array}{l}\text { Additional } \\
\text { imaging test } \\
\text { confirming } \\
\text { PE (n) }\end{array}$ & $\begin{array}{l}\text { Additional } \\
\text { imaging test } \\
\text { excluding } \\
\text { PE (n) }\end{array}$ & $\begin{array}{l}\text { Non-conclusive } \\
\text { additional } \\
\text { imaging } \\
\text { test (n) }\end{array}$ & $\begin{array}{l}\text { Anticoagulation } \\
\text { despite } \\
\text { non-diagnostic } \\
\text { results }\end{array}$ \\
\hline
\end{tabular}

\begin{tabular}{|c|c|c|c|c|c|c|c|c|c|}
\hline \multicolumn{10}{|c|}{ V-Q lung scanning* } \\
\hline Balan et al. 1997 & 82 & 33 & 40 & NP & NP & NP & NP & NP & 12 \\
\hline Chan et al. 2002 & 113 & 28 & 24,8 & NP & NP & NP & NP & NP & 4 \\
\hline Scarsbook et al. 2007 & 96 & 7 & 7.3 & $2(29)$ & CTPA & 0 & 2 & 0 & 0 \\
\hline Ridge et al. 2009 & 25 & 1 & 4 & $1(100)$ & СТРА & NP & NP & NP & NP \\
\hline Shahir et al. 2010 ** & 99 & 22 & 21 & $3(14)$ & СТРА & 1 & 2 & 0 & NP \\
\hline Revel et al. 2011 & 91 & 17 & 18.7 & NP & NP & NP & NP & NP & NP \\
\hline Scott et al. 2011 & 73 & 1 & 1.3 & NP & NP & NP & NP & $\mathrm{NP}$ & NP \\
\hline Sellem et al. 2013 & 116 & 22 & 18.9 & NP & NP & NP & NP & NP & NP \\
\hline Abele et al. $2013^{\ddagger}$ & 74 & 13 & 16.2 & $13(100)$ & СТPA & 1 & 9 & 3 & NP \\
\hline Astani et al. 2014 ** & 23 & 5 & 21.7 & NA & NA & NA & NA & NA & NA \\
\hline Cutts et al. $2014^{\dagger}$ & 183 & 6 & 3.3 & $2(33)$ & СТPA & 0 & 0 & 2 & 2 \\
\hline Ramsay et al. $2015^{\dagger}$ & 127 & 37 & 29.1 & $19(51)$ & CTPA & 1 & 8 & 10 & 4 \\
\hline Richard et al. 2015 & 77 & 7 & 9 & 1 & СТPA & 0 & 0 & 0 & 2 \\
\hline Sheen et al. 2017 & 225 & 21 & 9.3 & $9(43)$ & CTPA & 2 & 5 & 2 & NP \\
\hline Golfam et al. 2017 & 362 & 29 & 8 & NP & NP & NP & NP & NP & NP \\
\hline Armstrong et al. 2017 & 769 & 74 & 9.1 & NP & NP & NP & NP & NP & NP \\
\hline
\end{tabular}

Armstrong et al. $2017 \quad 7$

\section{CTPA}

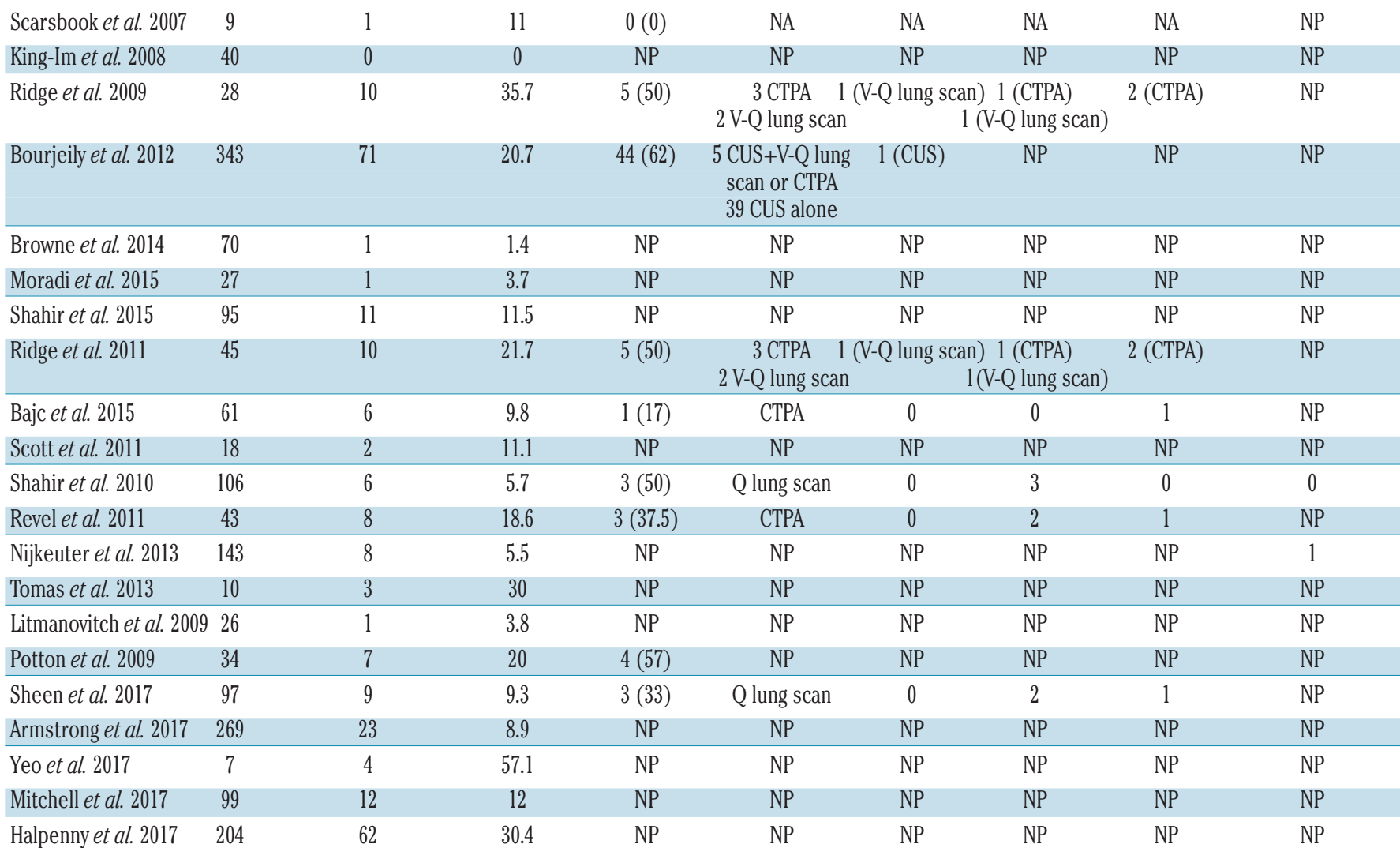

CTPA: computed tomography pulmonary angiography; V-Q scanning: ventilation-perfusion scanning; NP: not provided; NA: not applicable. PE: pulmonary embolism; CUR: compression ultrasonography; * non diagnostic V-Q lung scans were defined by intermediate and low probability scan results. ${ }^{1} 89$ low probability V-Q scans were considered as normal V-Q lung scans. ${ }^{*}$ non-diagnostic V-Q scans were defined as abnormal perfusion scans. ** very low PE probability V-Q lung scans were considered as normal V-Q lung scans. 
Table 4. Overview of studies on radiation exposure from CTPA or V-Q lung scanning in real-life patients.

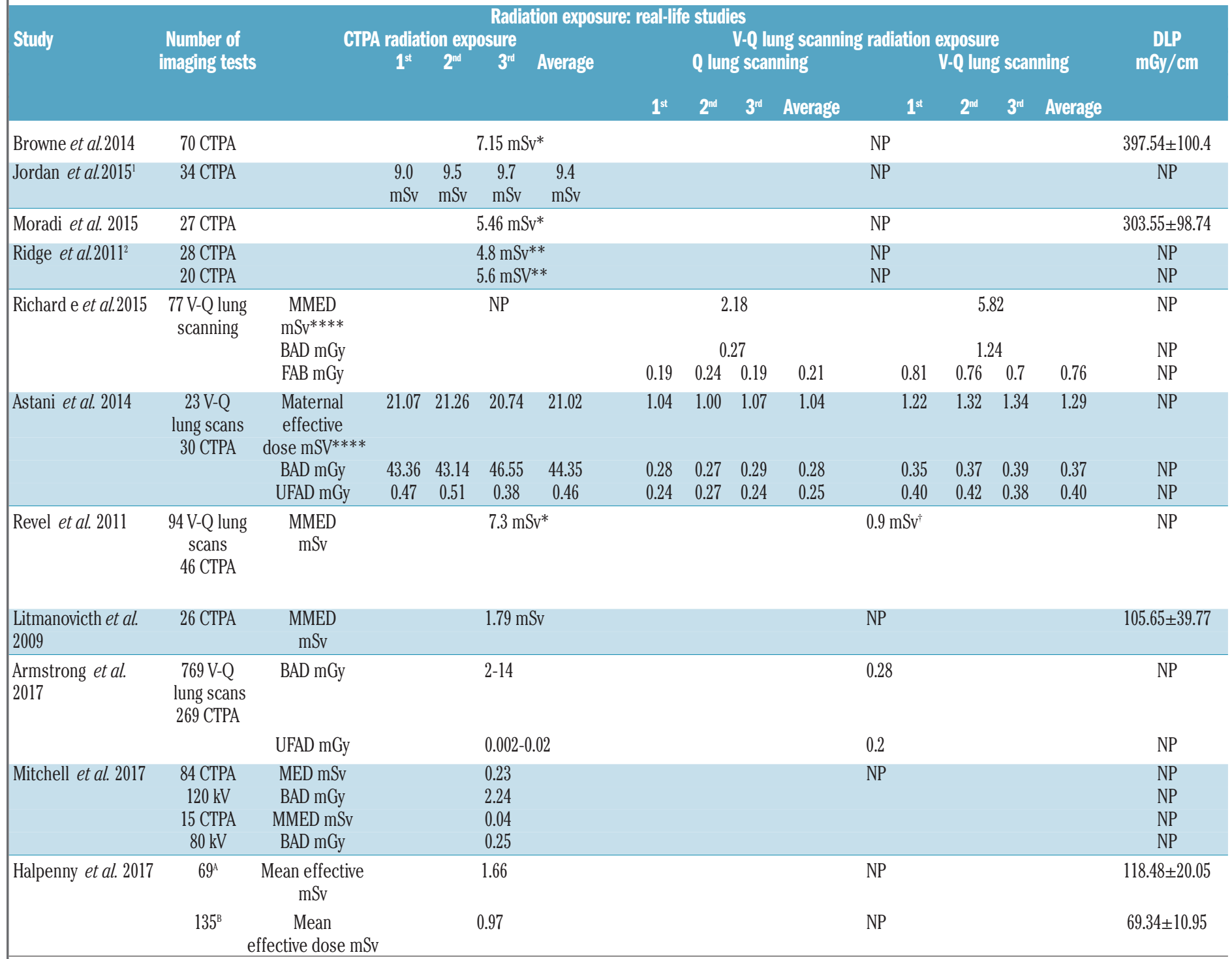

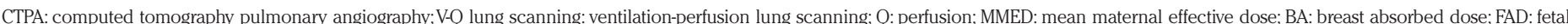

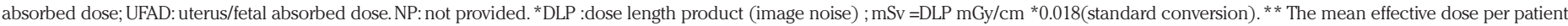

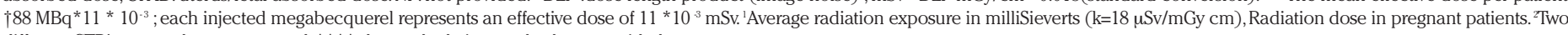
different CTPA protocols were assessed. ${ }^{* * *}$ dose calculation method not provided.

CTPA partly explains the recommendation of V-O lung scans by international guidelines for pregnant patients with suspected PE. The Society of Thoracic Radiology clinical practice guidelines have presented comparable radiation exposure doses to our findings. ${ }^{74}$ However, since the studies in our review did not provide all imaging protocol details or full disclosure of the mathematical formulas used, the reported radiation doses in Table 5 are neither comparable between studies nor reproducible. Moreover, mathematical body phantoms (Monte Carlo simulation) of pregnant patients were used instead of realistic physical phantoms in three of the CTPA phantom studies. ${ }^{65,66,68}$ The presented radiation exposure doses in both phantom and human studies should therefore be interpreted with great caution. Moreover, the risk of early breast cancer seems similar after VQ lung scanning and CTPA. $^{75}$

\section{State-of-the-art imaging techniques}

For the diagnosis of acute PE, accuracy and pulmonary arterial opacification are significantly improved by optimizing the CTPA protocol for the pregnant patient. This optimization includes a high flow rate ( 6 instead of 4 $\mathrm{mL} / \mathrm{s}$ ), a high volume (an approximately $25 \%$ increase) followed by saline flush, a high concentration of contrast medium (370 $\mathrm{mg} \mathrm{I} / \mathrm{mL}$ ), and shallow held inspiration (to avoid the Valsalva maneuver).$^{24}$ In the Leiden University Medical Center, the contrast volume and speed are titrated according to the patient's weight. Advised measures to reduce radiation dose include using a $100 \mathrm{kV}$ protocol ${ }^{76}$ and reduced $z$-axis technique with limited scan volume from just above the aorta to the basal lung fields (excluding the upper and lower marginal zones). ${ }^{77}$ For the diagnosis of acute PE with lung scintigraphy in pregnancy, a two-step protocol is suggested to minimize radiation. Initially, per- 
Table 5. Overview of studies on radiation exposure from CTPA or V-Q lung scanning in phantom studies.

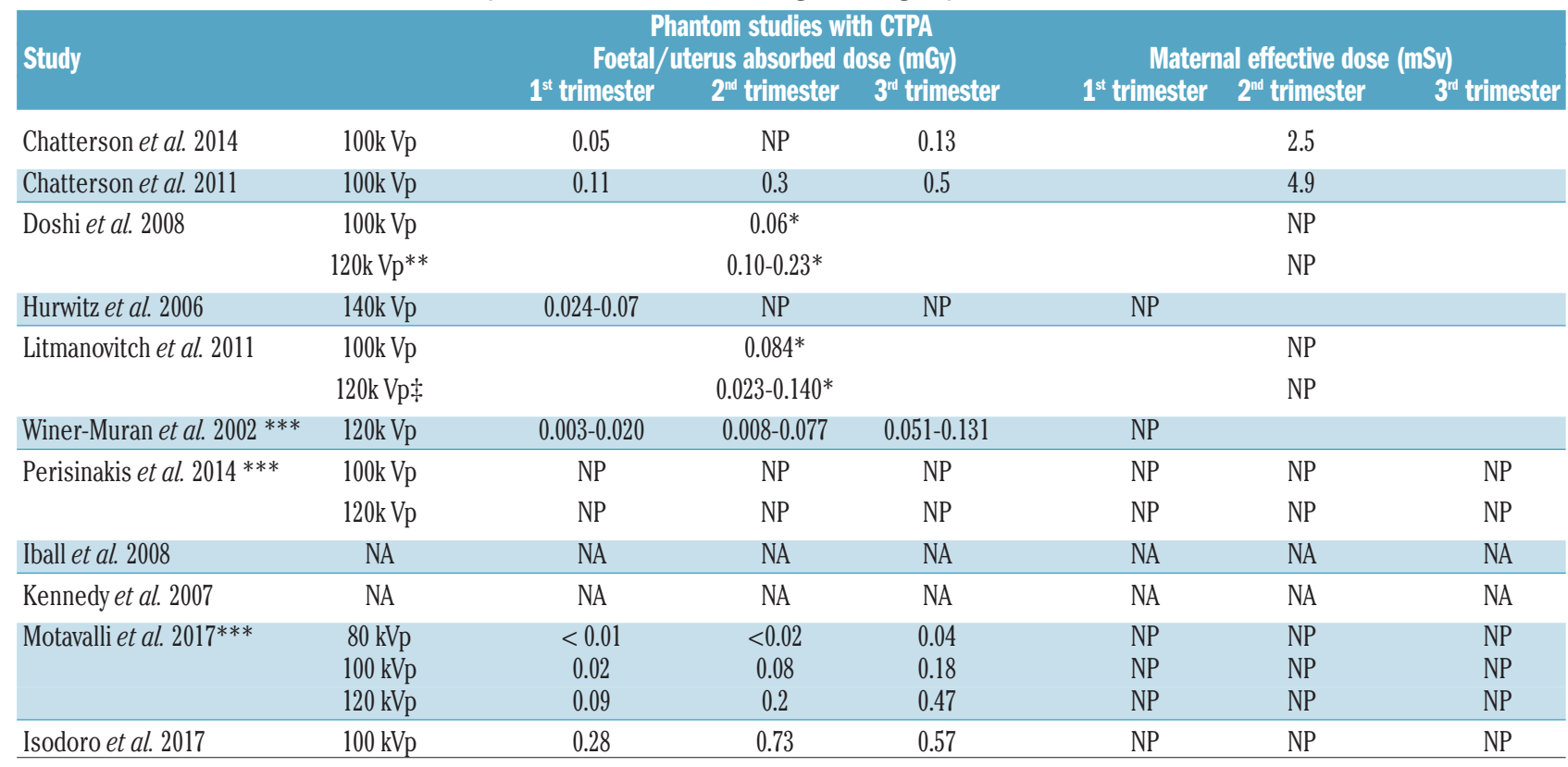

CTPA: computed tomography pulmonary angiography:Vp: kilovolt protocol; NP: not provided; NA: not applicable. *mean fetal absorbed dose; * ${ }^{*}$ two different CTPA protocols with $120 \mathrm{kV}$ were assessed; $¥$ three different CTPA protocols with $120 \mathrm{kV}$ were assessed; *** Monte Carlo simulation.

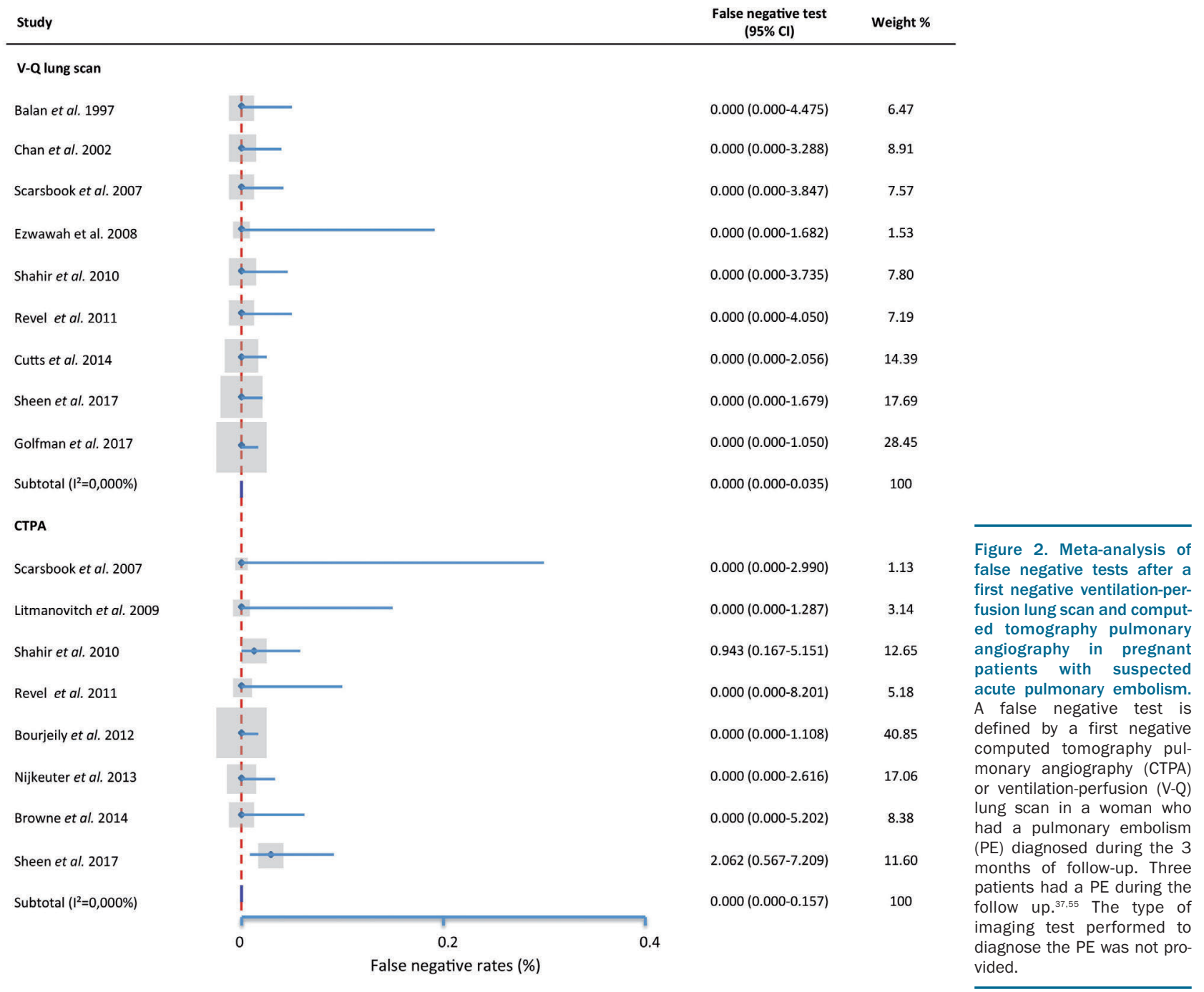


fusion-only scintigraphy should be performed using a reduced dose of ${ }^{99 m}$ Tc-MAA (approximately a quarter of the usual dose administrated for a one-step V/O scan). Because of the low frequency of co-morbid pulmonary disorders, $\mathrm{PE}$ can be excluded in most cases on the basis of a normal perfusion pattern. Ventilation images should only be performed in the case of abnormal perfusion images.

\section{Conclusion}

Based on the available data, direct comparisons of safety and efficiency between CTPA and V-O lung scanning do not seem valid. The available studies are based mostly on techniques that are outdated with regard to the current and presently evolving techniques, for both CTPA and V-O

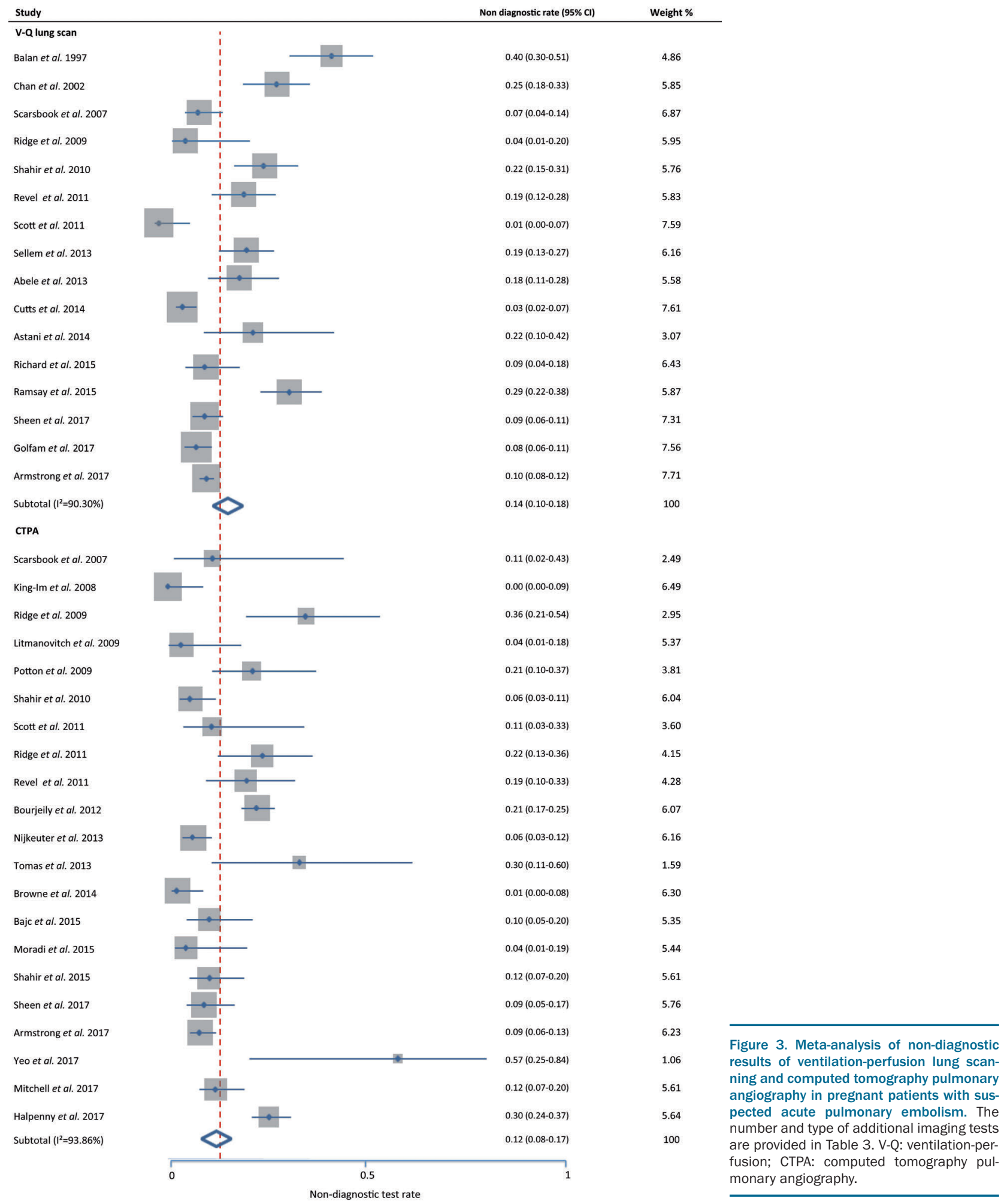


lung scanning. Our most important finding appears to be the very low rate of false negative test results for both imaging modalities, although the low disease prevalence among the studies prevents a solid evaluation of the sensitivity. Moreover, radiation doses associated with CTPA and $\mathrm{V}$-Q lung scanning are well below the safety threshold.
Depending on new developments and insights of pending studies, decisions regarding the imaging modality of choice should be based on local availability of techniques combined with use of optimal scan protocols tailored to the pregnant patient.

\section{References}

1. Guimicheva B, Czuprynska J, Arya R. The prevention of pregnancy-related venous thromboembolism. Br J Haematol. 2015;168(2):163-174

2. Say L, Chou D, Gemmill A, et al. Global causes of maternal death: a WHO systematic analysis. Lancet Glob Health. 2014;2(6): e323-333.

3. Tromeur C, van der Pol LM, Klok FA, Couturaud F, Huisman MV. Pitfalls in the diagnostic management of pulmonary embolism in pregnancy. Thromb Res. 2017;151 (Suppl 1):S86-S91

4. Huisman MV, Klok FA. How I diagnose acute pulmonary embolism. Blood. 2013;121(22):4443-4448.

5. Van der Pol LM, Mairuhu AT, Tromeur C, Couturaud F, Huisman MV, Klok FA. Use of clinical prediction rules and D-dimer tests in the diagnostic management of pregnant patients with suspected acute pulmonary embolism. Blood Rev. 2017;31(2):31-36

6. Cahill AG, Stout MJ, Macones GA, Bhalla S. Diagnosing pulmonary embolism in pregnancy using computed-tomographic angiography or ventilation-perfusion. Obstet Gynecol. 2009;114(1):124-129

7. Chan WS, Ray JG, Murray S, Coady GE, Coates G, Ginsberg JS. Suspected pulmonary embolism in pregnancy: clinical presentation, results of lung scanning, and subsequent maternal and pediatric outcomes. Arch Intern Med. 2002;162(10):11701175

8. PRISMA. The PRISMA statement http://www.prisma-statement.org/statement.htm. [cited Aug, 2015)].

9. DerSimonian R, Laird N. Meta-analysis in clinical trials. Control Clin Trials. 1986;7 (3):177-188.

10. Higgins JP, Thompson SG, Deeks JJ, Altman DG. Measuring inconsistency in metaanalyses. BMJ. 2003;327(7414):557-560

11. Abujudeh HH, Kaewlai R, Farsad K, Orr E, Gilman M, Shepard JA. Computed tomography pulmonary angiography: an assessment of the radiology report. Acad Radiol. 2009;16(11):1309-1315

12. Andreou AK, Curtin JJ, Wilde S, Clark A. Does pregnancy affect vascular enhancement in patients undergoing CT pulmonary angiography? Eur Radiol. 2008;18(12):27162722 .

13. Angulo VJ, Ramirez GA, Torres Gomez LG, Vargas GA, Cortes SL. [Pulmonary thromboembolism in obstetrics]. Ginecol Obstet Mex. 2004;72:400-406

14. Balan KK, Critchley M, Vedavathy KK, Smith ML, Vinjamuri S. The value of ventilation-perfusion imaging in pregnancy. $\mathrm{Br} \mathrm{J}$ Radiol. 1997;70(832):338-340.

15. Bourjeily G, Khalil H, Raker C, et al. Outcomes of negative multidetector computed tomography with pulmonary angio- graphy in pregnant women suspected of pulmonary embolism. Lung. 2012;190(1): $105-111$.

16. Browne AM, Cronin CG NiMhuircheartaigh J, et al. Evaluation of imaging quality of pulmonary 64-MDCT angiography in pregnancy and puerperium. AJR Am J Roentgenol. 2014;202(1):60-64.

17. Cutts BA, Tran HA, Merriman E, et al. The utility of the Wells clinical prediction model and ventilation-perfusion scanning for pulmonary embolism diagnosis in pregnancy. Blood Coagul Fibrinolysis. 2014;25(4):375 378.

18. Jordan EJ, Godelman A, Levsky JM, Zalta B, Haramati LB. CT pulmonary angiography in pregnant and postpartum women: low yield, high dose. Clin Imaging. 2015;39(2): 251-253.

19. King-Im JM, Freeman SJ, Boylan T, Cheow HK. Quality of CT pulmonary angiography for suspected pulmonary embolus in pregnancy. Eur Radiol. 2008:18(12):2709-2715.

20. Litmanovich D, Boiselle PM, Bankier AA, Kataoka ML, Pianykh O, Raptopoulos V. Dose reduction in computed tomographic angiography of pregnant patients with suspected acute pulmonary embolism. Comput Assist Tomogr. 2009:33(6):961-966.

21. Moradi M, Monfared LJ. Qualitative evaluation of pulmonary CT angiography findings in pregnant and postpartum women with suspected pulmonary thromboembolism. J Res Med Sci. 2015;20(11):1088-1093.

22. Moriarty JM, Bolster F, O'Connor C, et al. Frequency of nonthromboembolic imaging abnormalities in pregnant women referred for computed tomography pulmonary arteriography. Can Assoc Radiol J. 2015; 66(1):24-29

23. Ridge CA, McDermott S, Freyne BJ, Brennan DJ, Collins CD, Skehan SJ. Pulmonary embolism in pregnancy: comparison of pulmonary CT angiography and lung scintigraphy. AJR Am J Roentgenol. 2009;193(5): 1223-1227.

24. Ridge CA, Mhuircheartaigh JN, Dodd JD, Skehan SJ. Pulmonary CT angiography protocol adapted to the hemodynamic effects of pregnancy. AJR Am J Roentgenol. 2011;197(5):1058-1063.

25. Sellem A, Elajmi W, Mahjoub Y, Hammami $\mathrm{H}$. Diagnosis pulmonary embolism in pregnancy: contribution of lung scintigraphy. Retrospective study about 116 cases. MED NUCL. 2013;37(10-11):432-438.

26. Shahir K, McCrea JM, Lozano LA, Goodman LR. Reduced z-axis technique for CT pulmonary angiography in pregnancyvalidation for practical use and dose reduction. Emerg Radiol. 2015;22(6):651-656.

27. Abele IT, Sunner P. The clinical utility of a diagnostic imaging algorithm incorporating low-dose perfusion scans in the evaluation of pregnant patients with clinically suspected pulmonary embolism. Clin Nucl Med. 2013;38(1):29-32
28. Astani SA, Davis LC, Harkness BA Supanich MP, Dalal I. Detection of pulmonary embolism during pregnancy: comparing radiation doses of CTPA and pulmonary scintigraphy. Nucl Med Commun 2014;35(7):704-711

29. Bajc M, Olsson B, Gottsater A, Hindorf C, Jogi J. V/P SPECT as a diagnostic tool for pregnant women with suspected pulmonary embolism. Eur J Nucl Med Mol Imaging. 2015;42(8):1325-1330

30. Gruning T, Mingo RE, Gosling MG, et al Diagnosing venous thromboembolism in pregnancy. Br J Radiol. 2016;89(1062): 20160021

31. Hamilton EJ, Green AQ, Cook JA, Nash H Investigating for pulmonary embolism in pregnancy: five year retrospective review of referrals to the acute medical unit of a large teaching hospital. Acute Med. 2016;15(2): 58-62.

32. Ramsay R, Byrd L, Tower C, James J, Prescott M, Thachil J. The problem of pulmonary embolism diagnosis in pregnancy. Br J Haematol. 2015;170(5):727-728.

33. Revel MP, Cohen S, Sanchez O, et al Pulmonary embolism during pregnancy: diagnosis with lung scintigraphy or CT angiography? Radiology. 2011;258(2):590598

34. Richard MC, Lambert R, Rey E, Turpin S. Is perfusion scintigraphy sufficient in pregnant or post-partum women? Med Nucl. 2015;39(6):479-485.

35. Scarsbrook AF Bradley KM, Gleeson FV Perfusion scintigraphy: diagnostic utility in pregnant women with suspected pulmonary embolic disease. Eur Radiol. 2007;17(10): 2554-2560.

36. Scott K, Rutherford N, Fagermo N, Lust K Use of imaging for investigation of suspected pulmonary embolism during pregnancy and the postpartum period. Obstet Med. 2011:4(1):20-23.

37. Shahir K, Goodman LR, Tali A, Thorsen KM, Hellman RS. Pulmonary embolism in pregnancy: CT pulmonary angiography versus perfusion scanning. AJR Am J Roentgenol. 2010;195(3):W214-W220.

38. Bowlen L, Hofman M, Santos P. A retrospective review of lung ventilation and perfusion $(\mathrm{V} / \mathrm{Q})$ scanning in pregnant women. Intern Med J. 2011;Conference:41.

39. Butt N, Coffey J, Hill JC. Pulmonary embolism imaging in pregnancy - a 3 year retrospective review. Eur J Nucl Med Mol Imaging. 2011;Conference: S401.

40. Edwards R. Imaging techniques for pregnant patients for suspected $\mathrm{PE}-\mathrm{a}$ retrospective review. Inter Med J. 2012;Conference:18-19.

41. Hufton A, Albert P, Phitidis ME, Kwok A Duffy N. Investigating suspected pulmonary embolism (PE) in pregnancy - review of practice at Aintree University Hospital. Eur Respir J. 2015:(1):52.

42. Hullah P, Harris B, Hibbert M. A case review study of investigating for pulmonary 
embolism in pregnancy. Respirology. 2011;16(Suppl 1):37-86

43. Ma HY, Jia CP, Moadel R, Freeman LR. Evaluation for pulmonary emboli in pregnancy. Clin Nucl Med. 2014;Conference: 313.

44. Ma HY, Natenzon A, Sheen J-J, et al. Evaluation of pulmonary emboli in pregnancy. J Nucl Med. 2015;Conference.

45. Nijkeuter M, Tan M, Middeldorp S, Kroft LJM, Beenen L, Huisman MV. Safety of ruling out pulmonary embolism (PE) in pregnancy by computed tomography pulmonary angiography (CTPA). J Thromb Haemost. 2013;Conference:130.

46. Potton EC, Marsh S, Hasford C. Incidence of non-diagnostic CT pulmonary angiography images in the pregnant population: a 4-year experience. Thorax. 2009; Conference:A88.

47. Roseverne L, Schembri G, Roach P. Value of ventilation SPECT scintigraphy in pregnant patients with suspected PE. Intern Med J. 2011:Conference(var.pagings):16.

48. Slim I, Ben GT, Yeddes I, et al. Lung perfusion scintigraphy: diagnostic utility of pulmonary embolism during pregnancy. Eur J Nucl Med Mol Imaging. 2012;Conference: S484.

49. Tomas HS, Phillips J, Bebbington N, Ogunremi T, Guest P. Investigating pulmonary embolism (PE) in pregnancy: single photon emission computed tomography ventilation-perfusion scintigraphy (SPECT VQ). Eur J Nucl Med Mol Imaging. 2013; Conference:S386.

50. Vanes NK, O'Connor H, Baillie P, Sinha A. Diagnosis and management of suspected venous thromboembolism in pregnancy: Experience in a birmingham maternity unit. Arc Dis Child Fetal Neonatal Ed. 2014; Conference:A125.

51. Ezwawah O, Alkoteesh J, Barry JE, Ryan M. Pulmonary embolism in pregnancy: is nuclear medicine imaging still a valid option? Ir Med J. 2008;101(9):281-284.

52. Armstrong L, Gleeson F, Mackillop L, Mutch S, Beale A. Survey of UK imaging practice for the investigation of pulmonary embolism in pregnancy. Clin Radiol. 2017;72(8):696-701.

53. Golfam M, Pham X, Samaan S, Moher D. Optimization of lung scintigraphy in pregnant women at the Ottawa Hospital, Canada. J Nucl Med. 2017;58(Suppl1):1209.

54. Mitchell DP, Rowan M, Loughman E, Ridge CA, MacMahon PJ. Contrast monitoring techniques in CT pulmonary angiography: An important and underappreciated contributor to breast dose. Eur J Radiol. 2017;86: 184-189.
55. Sheen JJ, Haramati LB, Natenzon A, et al. Performance of low dose perfusion scintigraphy and CT pulmonary angiography for pulmonary embolism in pregnancy. Chest. 2018;153(1):152-160

56. Yeo JH, Zhou L, Lim R. Indeterminate CT pulmonary angiogram: why and does it matter? J Med Imaging Radiat Oncol. 2017;61(1):18-23

57. Halpenny D, Park B, Alpert J, et al. Low dose computed tomography pulmonary angiography protocol for imaging pregnant patients: can dose reduction be achieved without reducing image quality? Clinical Imaging. 2017;44:101-105.

58. Chatterson LC, Leswick DA, Fladeland DA Hunt MM, Webster S, Lim H. Fetal shielding combined with state of the art CT dose reduction strategies during maternal chest CT. Eur J Radiol. 2014;83(7):1199-1204

59. Chatterson LC, Leswick DA, Fladeland DA, Hunt MM, Webster ST. Lead versus bismuth-antimony shield for fetal dose reduction at different gestational ages at CT pulmonary angiography. Radiology. 2011;260 (2):560-567

60. Doshi SK, Negus IS, Oduko JM. Fetal radiation dose from CT pulmonary angiography in late pregnancy: a phantom study. $\mathrm{Br}$ J Radiol. 2008;81(968):653-658.

61. Hurwitz LM, Yoshizumi T, Reiman RE, et al Radiation dose to the fetus from body MDCT during early gestation. AJR Am J Roentgenol. 2006:186(3):871-876.

62. Iball GR, Kennedy EV, Brettle DS. Modelling the effect of lead and other materials for shielding of the fetus in CT pulmonary angiography. Br J Radiol. 2008;81(966):499503 .

63. Kennedy EV, Iball GR, Brettle DS. Investigation into the effects of lead shielding for fetal dose reduction in CT pulmonary angiography. Br J Radiol. 2007;80(956):631638.

64. Litmanovich D, Tack D, Lin P-J, Boiselle PM, Raptopoulos V, Bankier AA. Female breast, lung, and pelvic organ radiation from dosereduced 64-MDCT thoracic examination protocols: a phantom study. AJR Am J Roentgenol. 2011;197(4):929-934

65. Perisinakis K, Seimenis I, Tzedakis A, Damilakis J. Perfusion scintigraphy versus 256-slice CT angiography in pregnant patients suspected of pulmonary embolism: comparison of radiation risks. J Nucl Med. 2014;55(8):1273-1280.

66. Winer-Muram HT, Boone JM, Brown HL, Jennings SG, Mabie WC, Lombardo GT. Pulmonary embolism in pregnant patients: fetal radiation dose with helical CT. Radiology. 2002;224(2):487-492

67. Isidoro J, Gil P, Costa G, Pedroso de Lima J, Alves C, Ferreira NC. Radiation dose comparison between V/P-SPECT and CTangiography in the diagnosis of pulmonary embolism. Phys Med. 2017:41:93-96.

68. Motavalli LR, Azghadi EH, Hakimabad HM, Akhlaghi P. Pulmonary embolism in pregnant patients: assessing organ dose to pregnant phantom and its fetus during lung imaging. Med Phys. 2017;44(11):6038-6046.

69. McCollough CH, Schueler BA, Atwell TD et al. Radiation exposure and pregnancy: when should we be concerned? Radiographics. 2007;27(4):909-917.

70. van Mens TE, Scheres LJ, de Jong PG Leeflang MM, Nijkeuter M, Middeldorp S. Imaging for the exclusion of pulmonary embolism in pregnancy. Cochrane Database Syst Rev. 2017;1:CD011053.

71. Dronkers CEA, van der Hulle T, Le Gal G, et al. Towards a tailored diagnostic standard for future diagnostic studies in pulmonary embolism: communication from the SSC of the ISTH. J Thromb Haemost. 2017;15(5): 1040-1043.

72. van der Hulle T, Cheung WY, Kooij S, et al Simplified diagnostic management of suspected pulmonary embolism (the YEARS study): a prospective, multicentre, cohort study. Lancet. 2017;390(10091):289-297.

73. Konstantinides SV, Torbicki A, Agnelli G, et al. 2014 ESC guidelines on the diagnosis and management of acute pulmonary embolism. Eur Heart J. 2014;35(43):3033-3080.

74. Leung AN, Bull TM, Jaeschke $\mathrm{R}$, et al. American Thoracic Society documents: an official American Thoracic Society/Society of Thoracic Radiology clinical practice guideline--evaluation of suspected pulmonary embolism in pregnancy. Radiology. 2012;262(2):635-646.

75. Burton KR, Park AL, Fralick M, Ray JG. Risk of early onset breast cancer among women exposed to thoracic computed tomography in pregnancy or early postpartum. J Thromb Haemost. 2018;16(5):876-885

76. Schueller-Weidekamm C, Schaefer-Prokop CM, Weber M, Herold CJ, Prokop M. CT angiography of pulmonary arteries to detect pulmonary embolism: improvement of vascular enhancement with low kilovoltage settings. Radiology. 2006;241(3):899-907.

77. Shahir K, McCrea JM, Lozano LA Goodman LR. Reduced z-axis technique for CT Pulmonary angiography in pregnancy-validation for practical use and dose reduction. Emerg Radiol. 2015;22(6):651-656. 